\title{
Specific causes of death in miners and ex-miners of the Rhondda Fach 1950-80
}

\author{
L K ATUHAIRE, ${ }^{1}$ M J CAMPBELL, ${ }^{1}$ A L COCHRANE, ${ }^{2}$ M JONES, ${ }^{2}$ AND \\ F MOORE ${ }^{2}$
}

From the Department of Community Medicine and Medical Statistics, ${ }^{1}$ Southampton, and the MRC Epidemiology Unit, ${ }^{2}$ Cardiff, UK

ABSTRACT The specific causes of death for miners and ex-miners of the Rhondda Fach have been examined in detail using the data base provided by the 30 year follow up. The main findings are the lower specific mortality for those with category $\mathrm{A}$, compared with those with categories $0,1,2$, and 3 , for all circulatory diseases (particularly ischaemic heart disease) and the raised mortality for gastric cancer. These results are surprising because a high proportion of those with, especially, categories 2 and 3 developed category A during the 30 years but fail to show the specific death rates typical of those with category A. Possible reasons for this are discussed and an explanation put forward.

The specific causes of death of men in mining populations have been rather neglected, mainly because so many deaths are needed when they are broken down by occupation, age, and pneumoconiosis category to make sense of the results, and partly because of distrust about the accuracy of such data. We agree about the inaccuracy but doubt whether it leads to bias in relation to category of pneumoconiosis with which we are chiefly concerned here. We therefore took the plunge.

\section{Material}

The material used is the results of the 30 year follow up of the men in the Rhondda Fach, ${ }^{1}$ which forms an excellent data base.

\section{Results}

\section{SIMPLE PNEUMOCONIOSIS}

Table 1 summarises the results for some specific cause of death. Although there is a dramatic rise in the SMR for deaths from pneumoconiosis, the number of deaths is so small (less than $10 \%$ of all deaths in category 3) that it has little effect on the SMRs for all causes for the four categories $(0,1,2$, and 3$)$ which remain similar.

The SMRs for deaths from bronchitis are more interesting. There is no evidence of an increase in SMR

Accepted 3 December 1985 with category of pneumoconiosis. Since category is closely related to dust dosage we concluded that there is no support for the widely held belief that exposure to coal dust increases bronchitis mortality $\left(\chi^{2}{ }_{1}=\right.$ $0.272, p>0.5$ ). This also supplies some second rate evidence to support the idea, widely expressed by one of us (ALC), that there is no correlation between increase of category of simple pneumoconiosis and pulmonary disability. Similarly, the SMRs for all cancers $\left(\chi^{2}{ }_{1}=0.85, \mathrm{p}>0.3\right)$ and gastric cancer $\left(\chi^{2}{ }_{1}=0.95\right.$, $\mathrm{p}>0.3)$ which show a slight, though statistically insignificant, downward trend do not support the view held by some that exposure to coal dust increases mortality from gastric and other cancers of the digestive organs. The lack of downward trend with category for all circulatory diseases $\left(\chi^{2}{ }_{1}=0.23\right.$, $\mathrm{p}>0.5)$ and ischaemic heart disease $\left(\chi^{2}{ }_{1}=0.22\right.$, $\mathrm{p}>0.5)$ are important when the specific causes of death of those with $\mathrm{A}$ shadows are considered. Finally, the upward trend for violent deaths is somewhat surprising, though the numbers concerned are small, and actually the test for linear trend fails to reach significance $\left(\chi^{2}{ }_{1}=1 \cdot 59, \mathrm{p}>0 \cdot 2\right)$. It is presumably related to the fact that those with the higher categories of simple pneumoconiosis spent a longer time working on the coal face and were therefore more likely to suffer accidents.

\section{PROGRESSIVE MASSIVE FIBROSIS (PMF)}

The results for PMF are summarised in table 2. The relatively low SMR for all causes of those with cate- 
Table 1 SMRs for all causes of death and for some specific causes related to category of simple pneumoconiosis: miners and ex-miners in the Rhondda Fach followed up for 30 years. (Number of death in parentheses)

\begin{tabular}{|c|c|c|c|c|}
\hline \multirow[t]{2}{*}{ Cause } & \multicolumn{4}{|c|}{ Catergory of simple pneumoconiosis } \\
\hline & 0 & 1 & 2 & 3 \\
\hline $\begin{array}{l}\text { All causes } \\
\text { Pneumoconiosis } \\
\text { Bronchitis } \\
\text { All cancers } \\
\text { Gastric cancers } \\
\text { Cancer of trachea, bronchus, \& lung } \\
\text { All circulatory } \\
\text { Ischaemic heart disease } \\
\text { Violence }\end{array}$ & $\begin{array}{l}121 \cdot 2(1897) \\
314 \cdot 5(14) \\
218 \cdot 6(248) \\
93 \cdot 2(318) \\
152 \cdot 5(69) \\
76 \cdot 5(100) \\
118 \cdot 7(939) \\
119 \cdot 3(554) \\
125 \cdot 3(63)\end{array}$ & $\begin{array}{l}117 \cdot 8(512) \\
398 \cdot 0(5) \\
232 \cdot 0(75) \\
81.9(76) \\
119.8(15) \\
62.7(22) \\
115 \cdot 2(255) \\
111.7(143) \\
134.9(17)\end{array}$ & $\begin{array}{r}121 \cdot 2(399) \\
2152 \cdot 6(20) \\
248 \cdot 7(60) \\
89 \cdot 7(64) \\
137 \cdot 4(13) \\
91 \cdot 5(25) \\
107 \cdot 1(179) \\
98 \cdot 5(96) \\
172 \cdot 7(17)\end{array}$ & $\begin{array}{l}129 \cdot 6(212) \\
4008 \cdot 8(19) \\
203 \cdot 5(24) \\
79 \cdot 6(30) \\
102 \cdot 8(5) \\
85 \cdot 8(13) \\
125 \cdot 0(102) \\
135 \cdot 1(66) \\
170 \cdot 3(9)\end{array}$ \\
\hline
\end{tabular}

Many other specific causes of death have been scanned. The numbers in the subgroups are small and show no interesting trends. Further details are obtainable from LKA.

gory $\mathrm{A}$, comparable with those with simple pneumoconiosis, has been described in many follow up studies of miners and ex-miners, ${ }^{23}$ but it is of great interest that it is still there after 30 years when the numbers of deaths from pneumoconiosis in the category A group is now fairly large- 48 .

More surprising are the slightly raised SMRs for all cancers and the appreciably raised SMR for that of gastric cancer in particular. This is in pronounced contrast to the findings for simple pneumoconiosis. Similarly, the low SMRs for all circulatory causes and ischaemic heart disease, in comparison with those for simple pneumoconiosis, are striking. The differences are significant for all circulatory diseases $\left(\chi^{2}{ }_{1}=7 \cdot 30\right.$, $\mathrm{p}<0.01)$ and for ischaemic heart disease $\left(\chi^{2}{ }_{1}=6.31\right.$, $\mathrm{p}<0.02)$. The pronounced fall in the violence SMR is less surprising, as most of those with category $\mathbf{A}$ probably leave the coal face and possibly mining, so avoiding mining accidents.

It is easy to say that the relatively low SMR for all causes may be mathematically explained by calling attention to the fall in the SMRs for all circulatory causes and those for ischaemic heart disease, but this does not explain the "why" and the "how." The problem of explanation is made even more difficult if looked at from a cohort point of view. For example, consider the original cohort of category $3 \mathrm{~s}$. In the $\mathbf{3 0}$ years during which the cohort was followed up many would have developed A shadows and would be expected to take over the specific death rate characteristics of those with A shadows. Instead they retain the original specific death rates of their original cohort, except for deaths from pneumoconiosis. How is this possible?

There are in general three ways in which the development of the specific disease pattern of the population from which it is derived may be influenced: by competition, by prevention, and by selection.

Fairly simple reasoning makes it clear that if the incidence of A shadows influenced the specific death rate of ischaemic heart disease in the cohort by competition or by prevention, it must have influenced the specific death rate of ischaemic heart disease in the original cohort, making it increasingly similar to that of those with A shadows. The only explanation that seems to fit is that of selection. This would mean that the original cohort of, for example, those with category 3 would be divided according to some factor associated with the risk of ischaemic heart disease. Those with a low (or high) value of a particular risk

Table 2 SMRs for all causes and for some specific causes related to those with simple pneumoconiosis categories combined, and categories $A$ and $B C$ : miners and ex-miners in the Rhondda Fach followed up for 30 years. (Number of deaths in parentheses)

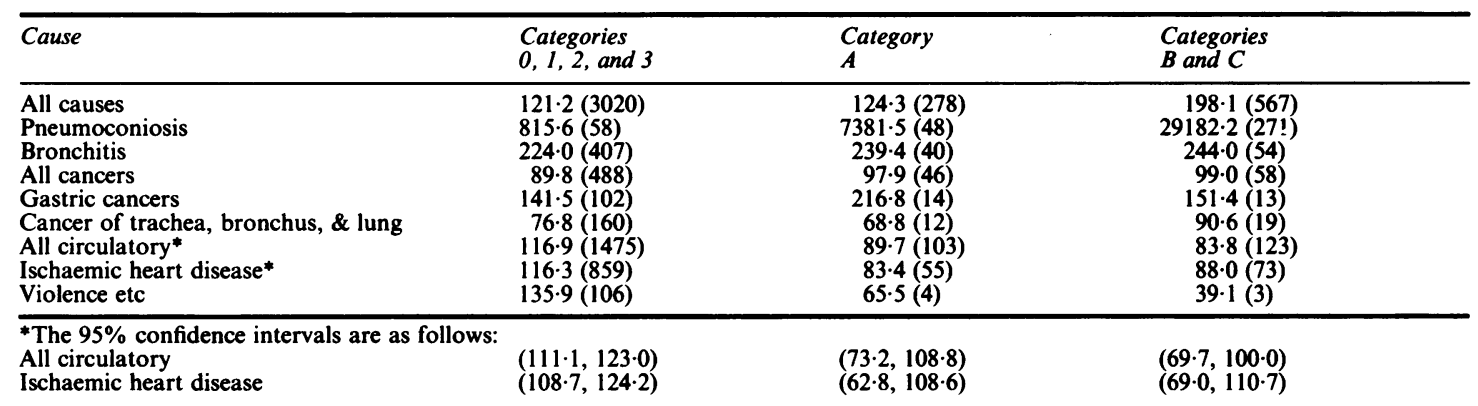


factor for ischaemic heart disease would be attacked but not the remainder. If the two groups retained their original potential regarding the death rate from ischaemic heart disease the specific death rate of the original cohort would not be disturbed.

One rather superficial point may be made against the "selection" hypothesis. It could be argued that after 30 years nearly everyone in the original cohort of, for example, those with category 3 would develop PMF and therefore the original cohort of category $3 \mathrm{~s}$ must take on the characteristics of the specific death rates of those with at least category $\mathbf{A}$. The answer to this is twofold: (1) if an attack rate of PMF of $3 \%$ a year on those with categories 2 and 3 in the original cohort is assumed there would still be about $40 \%$ of the cohort not attacked after 30 years; and (2) a secondary defence of the selection hypothesis would be that there may be some threshold in the value of the characteristic determining an attack of PMF, above or below which no attack is likely.

This result of our discussion is important as two of us (ALC and FM) reached a similar conclusion from considering some very different epidemiological data. ${ }^{4}$ We are rather forced to put forward the hypothesis that, in addition to category of pneumoconiosis, a low risk factor in the risk of developing ischaemic heart disease is an important factor in the aetiology of PMF.

The next step is clearly to investigate any overlap in what is known about the aetiology of PMF and that of ischaemic heart disease. This will be attempted in a subsequent paper.

\section{References}

${ }^{1}$ Atuhaire LK, Campbell MJ, Cochrane AL, Jones M, Moore F. Mortality of men in the Rhondda Fach 1950-80. Br J Ind Med 1985;42:741-5.

${ }^{2}$ Cochrane AL, Haley TJL, Moore F, Hole D. The mortality of men in the Rhondda Fach 1950-70. Br J Ind Med 1979;36:15-22.

${ }^{3}$ Jacobsen M. Dust exposure, lung diseases and coalminers mortality. Edinburgh: University of Edinburgh, 1976. (PhD thesis.)

${ }^{4}$ Cochrane AL, Moore F, Moncrieff CB. Are coalminers with low "risk factors" for ischaemic heart disease at greater risk of developing progressive massive fibrosis? Br J Ind Med 1982;39:265-8. 